\title{
Gamaencefalografía con Tc - 99m DTPA en el Diagnóstico de la Ventriculitis
}

\author{
Dies. Enrique Olea G.1, Alvaro Palma F.2, Gilda Guzmán M.2 \\ María I. Robinson 0.2, Rodolfo Hott $1 .^{2}$
}

\section{Gammaencephalography with Tc $99 \mathrm{~m}$ in the Diagnosis of Ventriculitis}

\begin{abstract}
The importance of early diagnosis of ventriculitis is emphasized. It is equally important to have means for treatment, evaluation and late results.

A preliminary study of gammaencephalography with tc 99 - DTPA is shown. This method has been very successful in the follow up of this disease, being also hamless fast and inexpensive.
\end{abstract}

Es conocida la alta frecuencia relativa de las complicaciones seṕticas en los procedimientos de derivación del líquido céfalo raquídeo (LCR), ya sea ventrículo-atriales, como ventriculo-peritoneales y en los meningo y mielomeningoceles rotos espontáneamente o intervenidos. No son tampoco infrecuentes en post operatorios de tumores intracraneanos, colección subdural del lactante, meningitis bacteriana, etc., como se apreciará en nuestra casuística. De estas complicaciones sépticas, la más temida por su alta mortalidad es la ventriculitis purulenta o bacteriana, cuyo diagnóstico precoz es de fundamental importancia para tomar oportunamente las medidas terapéuticas del caso (extracción del sistema derivativo, instalación de un dretıaje ventricular externo, tratamiento antibiótico intraventricular, etc.). Elło no siempre es fácil dada la normal reacción citoquimica del LCR luego de una intervención y en sentido estricto, requiere la existencia de cultivos positivos en el LCR ventricular para su confirmación.

\footnotetext{
1 Servicio Medicina Nuclear, Hosp. J.J. Aguirre.

${ }^{2}$ Servicio Medicina Nuclear, Instituto Neurocirugía.
}

La ventriculitis puede presentar diferentes etiologías (bacteriana, actínica, química). Corresponde a la inflamación de las cavidades ventriculares (ple$x o$, ependimo, $y$ tejido sub ependimario) y su evolución puede conducir al tabicamiento de ella, a la destrucción del plexo y, eventualmente, a la creación de zonas curadas y otras activas dentro de un mismo sistema ventricular. De las etiologias mencionadas, la que nos interesa es la bacteriana. En estos casos, si bien no siempre hay un cuadro clínico característico (irritabilidad, fiebre, peritonismo, supuración en el trayecto de la derivativa, etc.) el criterio más universalmente aceptado es el aumento mantenido de las células en el LCR, con hipoglucorraquia. No siempre hay cultivo positivo pero es, en definitiva, el único elemento que certifica el diagnóstico.

La visualización del sistema ventricular inflamado mediante gamaencefalografía con Tc - Pertecnetato ha sido ya descrita por otros autores $^{2-3-4-5}$. Sin embargo, este método carece de especificidad.

Estimulados por los hallazgos de Daly $y$ Patton ${ }^{1}$, hemos querido evialuar la utilidad de la Gamaencefalografía (GEG) con Tc 99m .. DTPA, en el diagróstico de ventriculitis, pues aportaría 
otro parámetro, probablemente más precoz, en su diagnóstico. Creemos que puede utilizarse además como criterio de curación, especialmente en casos fue no cumplen con las condiciones arbitrariamente establecidas $y$ actualmente en uso (5 a 10 muestras de LCR sucesjvas, con cultivo negativo y con menos de 10 células). Presentamos aquí una serie preliminar que es alentadora en estos aspectos.

\section{MATERIAL Y METODO}

Se estudiaron 25 pacientes del Instituto de Neurocirugia de Santiago mediante GEG con Tc $99 \mathrm{~m}$ - DTPA, todos ellos con el diagnóstico presuntivo de ventriculitis (Tabla 1). Las edades isctuaron entre 1 mes $y$ 48. affos $y$ fueron 15 hombres y 10 mujeres. De ellos 18 correspondian ai yupo etario de 1 a 11 meses; 5 a 1 - 10 años; $y$ : mayores de 10 años de edad.

\section{Tobla $J$.}

Distribueicia de 25 cosas con diagnóstico presuntivo de vedr: oculi, $j$, estudiados con Gamaencefalografia con

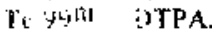

Hidr: refalia derivada Meningitis bacteriana

Mielomeningocele operado Colection sub dural operada

Tuinor cerebral uperado

$\operatorname{TOT} \Lambda \mathbf{L}$

El diagnóstico de ventriculitis se confirmó en definitiva mediante estudio bacteriológico del LCR ventricular en sólo 14 de estos pacientes (Tabla 1 ). El germen responsable del cuadro en este grupo se muestra en la Tabla 2 , y la mayor incidencia correspondió a la Pseudomona Aeruginosa.

\section{Tabb 2.}

Diagnóstico bacteriológico en 14 casos de ventriculitis, cstudiados mediante Gamaencefalografía con Tc $99 \mathrm{~m}$ DTPA.

\section{Bacteriología}

No Casos

Pseudomona Aeruginosa

Staphylococcus aureus

Enterobacter

Candida albicans

E. Coli

Serratia

Klebsiella

TOTAL

\section{bingnóstiso clinico}

Casos cotifirmados gicamente No

7

3$$
\text { ] }
$$$$
14
$$

El número total de exámenes efect uados en esta población de 14 pacientes fue de 23 . Se utilizó en todos ellos una Gamacámara Picker modelo DYNA $4 / 12$ de 19 fotomultiplicadores, con un colimador de baja energía y alta resolución. La imagen se obtuvo acumulando $500 \mathrm{~K}$ en un nivel de energia de $140 \mathrm{kw}$ y $10 \%$ de ventana. La molécula marcada con el radioisótopo Tc $99 \mathrm{~m}$, es el ácido dietiltriaminopentacético (DTPA), cuya característica principal es la de quelar metales como el Tc. Esta molécula se obtuvo en forma de juego de reactivo, cuyo proveedor es la Comisión Chilena de Energía Nuclear. Las imágenes se obtuvieron inmediatamente de inyectado y 2 horas post inyección en las 4 proyecciones clásicas. Se inyectó por vía endovenosa una dosis que fluctuó entre 5 y 25 mCi, según la edad.

\section{RESULTADOS}

La GEG con Tc $99 m$ - DTPA fue negativa para ventriculitis en los 9 casos en que, en definitiva, se descartó este diagnóstico. En uno de ellos, sin embargo, mostró signos sugerentes de colección sub dural infectada (Fig. 1), lo que fue confirmado en la intervención, encontrándose un estafilococo dorado.

En los 14 casos restantes, las imágenes obtenidas fueron claramente sugerentes de la existencia de un cuadro inflamatorio ependimario y subependimario, al producirse concentración anormal del radiofármaco en toda o parte del área ventricular (Figs. 2 y 3). En ocasiones, es posible señalar la existencia de zonas ventriculares más comprometidas por el cuadro séptico, las que pueden variar durante la evolución. Este fenómeno corresponde a casos tabicados, con confirmación tomogrâfica y/o gamaventriculografía (GVG), en los que la infección quedó acantonada en determinados sectores (Figs. 4 - 5-6).

También fue posible esbozar un criterio gamagráfico de curación en los 2 casos que fueron seguidos en su evolución mediante este examen. En ellos, hubo desaparición casi total de las zonas de concentración anormal del radiofámmaco luego de 45 y 75 días de tratamiento, respectivamente (Fig. 7).

\section{COMENTARIO}

Es indudable la afinidad especial del Tc $99 \mathrm{~m}$ DTPA por las zonas inflamadas por infección (ventriculitis, empiema sub dural) como fue demostrado en anatomía patológica por Fulmer y col. ${ }^{4}$. El DTPA se fijaría selectivamente en el tejido inflamado por aumento del metabolismo de éste, como sugiere Rollo y col. ${ }^{6}$. Este hecho 


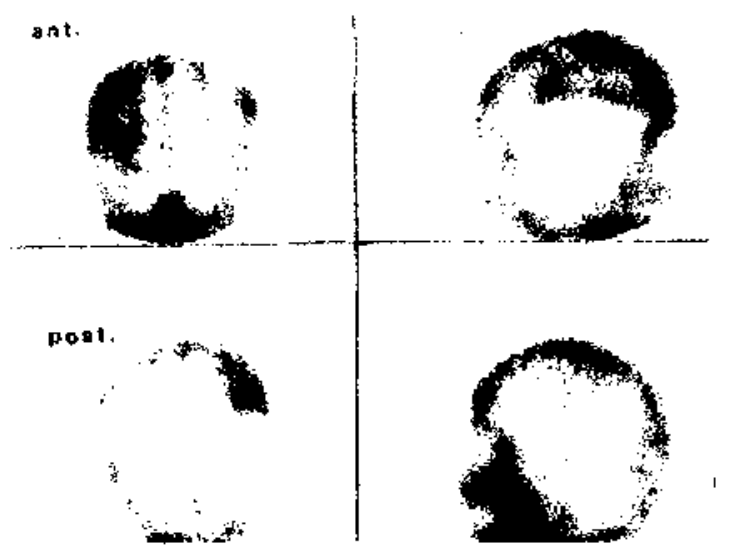

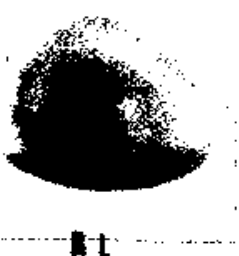

t

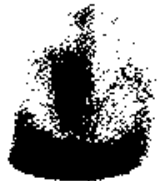

$A$

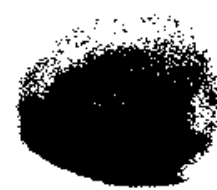

t.t

Fig. 3. Hidrocefalia complicada con ventricutitis en un lactante. E] Tc 99m - DTPA impregna ambos ventrículos laterales con predominio en el lado derecho.

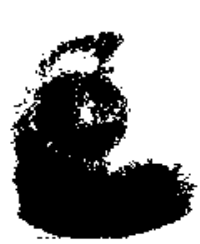

GiE G

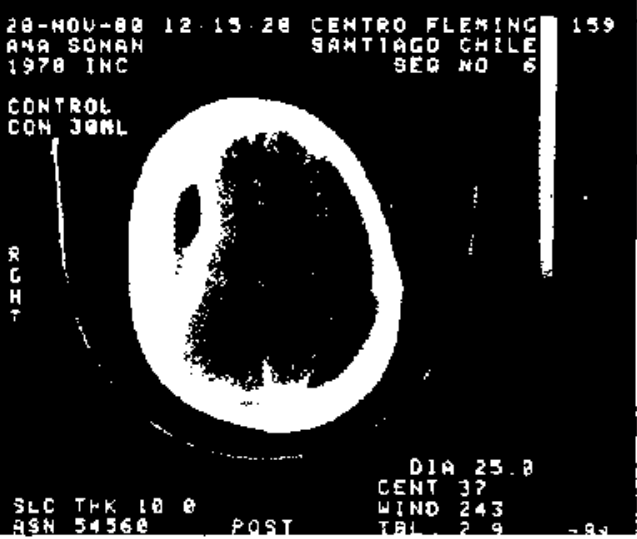

Fig. 1. A) GEG con Te 99m - DTPA que muestra concentración anormal fronto parietal alta izquierda sugetente de empiema sub dural. El diagnóstico se confirma con TAC (B) que muestra la cápsula en la zona sospechosa. En el otro hemisferio hay colección sub dural que también es sugerida en el examen isotópico.

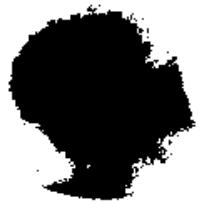

AI

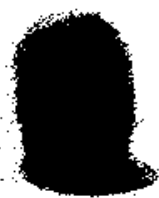

Ap

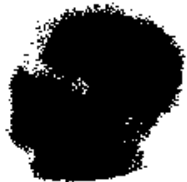

11
Fig. 2. Lactante portador de hidrocefalia acentuada, complicada con ventriculitis. Nótese‘ la impregnación anormal con el Tc 99m - DTPA de toda el área ventricular a ambos lados.
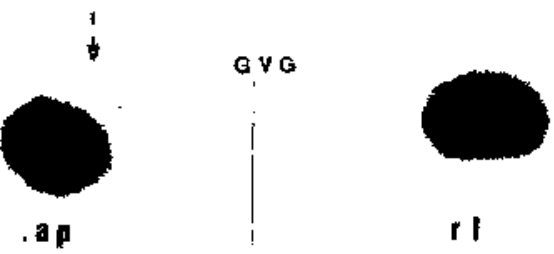

Fig. 4. Ventriculitis en tratamiento en un lactante con hidrocefalia. La GIG con Tc $99 \mathrm{~m}$ DTPA muestra persistencia del cuadro séptico en el ventrículo lateral derecho (arriba). La GVG con HSA Te $99 \mathrm{~m}$ (abajo) confirma el carácter tabicado del cuadro residual.

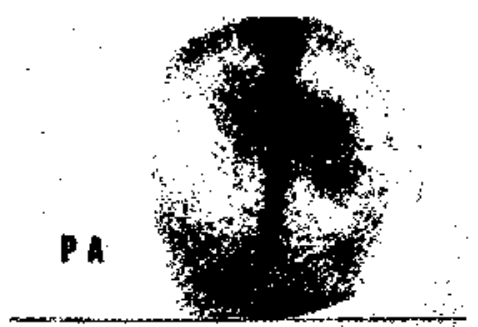

a

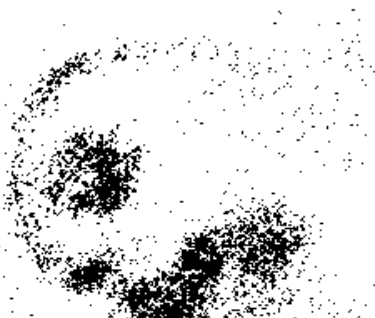

Fig. 5. Paciente de 13 años portador de ventriculitis en tratamiento cuya GEG con Te $99^{\mathrm{m}}$ - DTPA muestra predominio del cuadro séptico en la región posterior del hemisferio lateral derecho. 


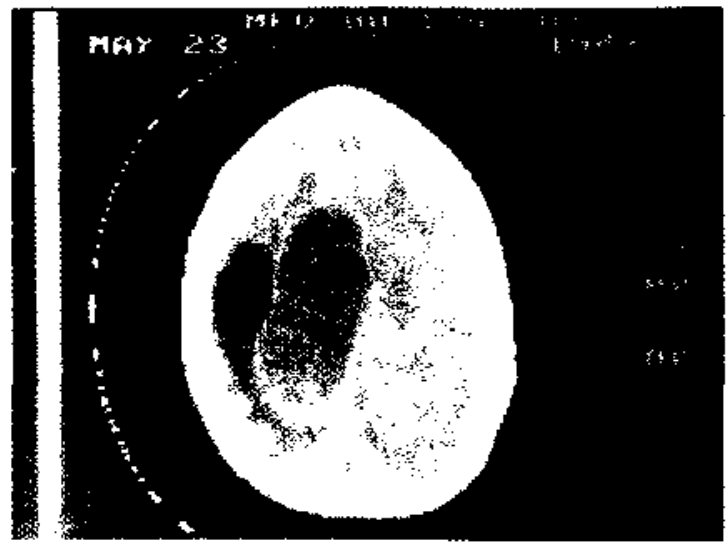

Fig. 6. TAC correspondiente at mismo paciente de la Figura 5. Nótese la irregularidad del perfil ventricular a ambos lados. Este examen sin embargo no permite determinar mayor o menor actividad del cuadro séptjco en Las diversas zonas. a
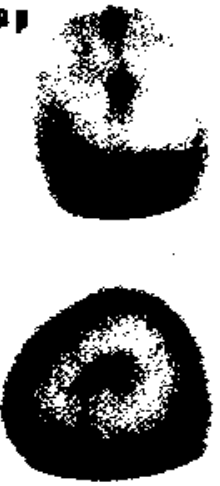

Pa

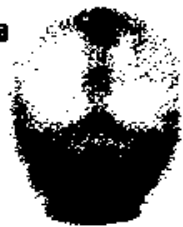

1.

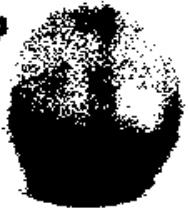

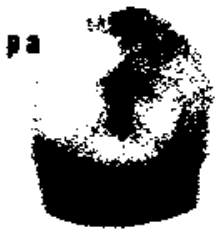

A
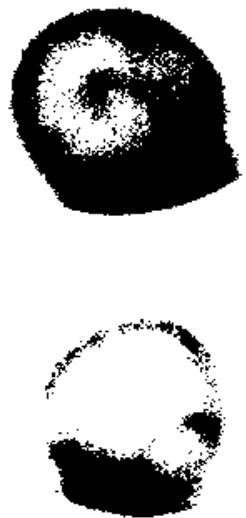

:

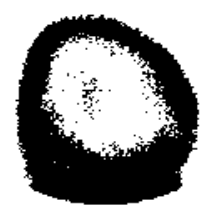

Fig. 7. A: GEG con Tc 49 m - DTPA que muestra activi. dad bilateral en un paciente portador de ventriculitis.

B: El mismo paciente 45 días después de iniciado tratamiento, en que el examen muestra una franca regresión de la lesión. puede ser aprovechado con ventajas en el diagnóstico precoz de una complicación séptica tan temida como la ventriculitis purulenta, lo que queda en evidencia con la serje preliminar que hemos presentado. Por otra parte, la confusión de estas imágenes con el plexo coroideo queda descartada, dada la absoluta falta de captación de DTPA por parte de estas estructuras. Está de más destacar la inocuidad, rapidez y economia del procedimiento. Además el aparente cerrado paralelismo existente entre su negativización y la curación clínica de los pacientes, hecho que necesitará de mayor confirmación, hace concebir esperanzas de que puede ser empleado como un elemento más en el criterio de curación de éstos.

El último aspecto que debe destacarse es su utilidad para seguir, durante la evolución, la aparición de tabicamientos intraventriculares, con el acantonamiento de la infección en una o más de estas cavidades. El método permite además la ubicación topográfica de estas zonas, to que facilita la reinstalación del drenaje extemo.

\section{RESUMEN}

Se destaca la importancia del diagnóstico pre$\operatorname{coz}$ de la ventriculitis. Es igualmente imperativo contar con medios que permitan seguir la evolución bajo tratamiento, así como certificar la curación, total o parcial, de este cuadro.

Se presenta una serie preliminar de gamaencefalografía con Tc - DTPA que se ha mostrádo muy alentadora en estos aspectos. Se destaca la inocuidad, rapidez y economía del método.

\section{REFERENCIAS}

' Daly, M.J. and Potton, D.F.: Ventriculitis: diagnosis with Technetium - 99m - DTPA. Nuclear Med. 19: $1243: 1978$.

${ }^{2}$ De Land, F.H., Wagner, H.N, Jr.: Atlas of Nuclear Medicine. Vol. 1 Philadelphia, W.B. Saunders, 1969, p. 48.

${ }^{3}$ Lee, H,K.: Unilateral pyogenic Yentriculitis. Nuclear Med. 18:403;1977.

4 Fuimer, L.R., Spakianakis, G.N.: Cerebral ventricle visualitation during brain scanning with $99 \mathrm{~m} \mathrm{Tc}_{\mathrm{c}}$ Pertechnetate. Nuclear Med. 15: 202; 1974.

5 Gildcy, D.L.: Various radionuclide patterns of cerebral inflamation in infants and children. Roentgenol 120: $247 ; 1974$.

${ }^{6}$ Rollo. F.D., Cavalieri, R.R., Born, M. ef al.: Comparative evaluatior of $99 \mathrm{~m} \mathrm{Tc} G \mathrm{Ch}, 99^{\mathrm{m}} \mathrm{Tc} 04$ and $99 \mathrm{~m} \mathrm{Tc}$ - DTPA as brain imaging agents. Radiology 132: 379; 1977. 